\title{
HUME E OS PROPÓSITOS DA FILOSOFIA
}

\author{
Marcos Ribeiro Balieiro* \\ marcos.balieiro@gmail.com
}

\begin{abstract}
RESUMO Hume é geralmente visto como um filósofo que, além de defender princípios céticos, pretendeu oferecer uma nova fundação para as ciências, baseada no estudo minucioso da natureza humana. De fato, não há dúvidas de que esse seria, para ele, um dos principais propósitos a que sua filosofia precisava servir. Procuraremos mostrar, no presente trabalho, que essa visão da filosofia humiana é, no fim das contas, limitada, já que perde de vista o fato de que, em textos posteriores, o filósofo escocês tentou estabelecer que a atividade filosófica deveria ser construída de modo a colaborar para a formação moral de seu público.
\end{abstract}

Palavras-chave Hume, filosofia escocesa, moral, século XVIII

ABSTRACT Hume is generally seen as a philosopher which, besides defending skeptical principles, intented to offer a new foundation for science, based on the accurate study of human nature. In fact, there is no doubt that

* Professor adjunto do Departamento de Filosofia da Universidade Federal de Sergipe (UFS). Doutor em filosofia pela Universidade de São Paulo (USP). Pesquisador do Grupo Hume e do Núcleo de Estudos e Pesquisas em Filosofia da História e Modernidade (NEPHEM). Artigo recebido em 08/11/2011 e aprovado em 30/11/2011.

1 Este artigo se beneficiou consideravelmente de algumas discussões travadas em encontros do Grupo Hume, de modo que devemos um enorme agradecimento aos colegas que participam dele (principalmente à Profa. Lívia Guimarães, que, além de ter colaborado para a reunião de boa parte dos humianos brasileiros, sempre nos honrou com observações proveitosas). Além disso, devemos observar que parte dos pontos que tentamos estabelecer aqui foram desenvolvidos pela primeira vez em nossa pesquisa de doutorado, orientada (com mais paciência do que merecemos) pela Profa. Maria das Graças de Souza, a quem também somos imensamente gratos. Finalmente, alguns colegas, como Maria Cecília Pedreira de Almeida e Antonio José Pereira Filho, devem ser lembrados por terem colaborado para a nossa percepção dos temas de que tratamos aqui.

KRITERION, Belo Horizonte, nº 124, Dez./2011, p. 385-396. 
he considers this to be one of the main purposes his philosophy should serve. In this work, we shall attempt to show that this is a limited view of Hume's thought, as it loses sight of the fact that, in posterior texts, he intended to establish the philosophical activity as something that should be developed in order to somehow form the moral character of its public.

Keywords Hume, Scottish philosophy, morals, 18th century

Na Introdução de seu Tratado da Natureza Humana, Hume nos oferece algumas informações importantes com relação àquilo que pretende que seja alcançado pela filosofia que proporá em seguida. Ele inicia com algumas considerações sobre o estado deplorável em que se encontram as ciências em seu tempo, apontando, logo a seguir, as infindáveis controvérsias de que nem mesmo os assuntos mais triviais podem escapar quando nenhum ramo do conhecimento tem fundamentos minimamente sólidos. Mostra ao leitor, ainda, que a desconfiança com relação à metafísica também seria resultado de incontáveis esforços desperdiçados e, portanto, algo que não ocorreria se as ciências fossem erigidas sobre base mais confiável.

Logo a seguir, Hume nos mostrará a que vem sua ciência da natureza humana. O que ele pretende é que ela possa, antes de qualquer outra coisa, providenciar um ponto de partida sólido, a partir do qual todas as outras ciências possam florescer. "É evidente", diz ele, "que todas as ciências têm uma relação, maior ou menor, com a natureza humana e, não importa quanto pareçam se distanciar dela, ainda retornam por uma passagem ou por outra"2 (HUME 2000, p. 4). Portanto, mesmo ciências que poderiam parecer completamente independentes de uma anatomia detalhada da mente humana, tais como matemática, física e religião natural, dependem, diz-nos Hume, da ciência que ele pretende propor. Áreas como lógica, política e crítica, então, que reconhecidamente dependem da condição humana de modo ainda mais visível, beneficiar-se-iam talvez mais ainda da tentativa, por parte de nosso filósofo, de explicar, senão os princípios últimos da alma, pelo menos certas características gerais da mente que é possível descobrir por meio da experiência. 
Nada disso, como sabe mesmo o leitor mais casual da obra de Hume, constitui grande novidade. A "Introdução" de sua primeira obra nos apresenta um jovem filósofo que tem a pretensão nada modesta de reconstruir a filosofia em bases significativamente diferentes daquelas em que ela até então se assentava $^{3}$. É esse o propósito declarado da filosofia humiana, ao menos no que diz respeito ao texto com o qual ela se inicia.

Desse modo, não causa qualquer estranheza que nosso filósofo, apesar de haver transmitido ao leitor, no "Advertisement", a informação de que considerará a aprovação do público como a maior recompensa por seus trabalhos (HUME 2000, p. 2), refira-se àquele que poderíamos chamar o homem comum como "a turba lá fora" (HUME 2000, p. 3) no texto da "Introdução". O público que o jovem Hume consideraria apropriado para julgar seu Tratado não era aquele que se voltava para as obras de filósofos apenas com o objetivo de serem exortados à prática da virtude, mas era composto por aqueles que se dedicavam efetivamente à prática da filosofia e da ciência. O teor do texto é preservado até o fim": na "Conclusão" do Livro 3, por exemplo, vemos a primeira formulação da famosa metáfora do pintor e do anatomista, que, nesse primeiro momento, tinha direção bastante distinta daquela que viria a adquirir na Seção 1 da Investigação sobre o Entendimento Humano:

$\mathrm{O}$ anatomista jamais deve emular o pintor e nem, em dissecações e retratos precisos das partes mais minúsculas do corpo humano, pretender dar a suas figuras qualquer atitude ou expressão graciosa ou encantadora. Há até mesmo algo de horrendo, ou ao menos mesquinho, na visão das coisas que ele apresenta, e é necessário que os objetos sejam vistos mais à distância, e mais escondidos do olhar, para torná-los encantadores para o olho e para a imaginação. Um anatomista, entretanto, é admiravelmente apropriado para aconselhar um pintor, e é até mesmo impraticável tornar-se excelente nesta última arte sem a assistência da primeira. ${ }^{5}$ (HUME 2000, p. 395)

3 Devemos observar, é claro, que esse não é um ponto em que se poderia dizer que Hume é mais pretensioso que vários outros autores. Uma leitura bastante rápida de textos como o Discurso do Método de Descartes, a "Epístola ao leitor" que inicia o Ensaio sobre o Entendimento Humano de Locke ou qualquer um dos dois prefácios da Crítica da Razão Pura de Kant, para ficar em apenas alguns exemplos, leva-nos a crer que o espírito de inovação, muitas vezes acompanhado de um desprezo algo temerário por ao menos boa parte dos autores antecedentes, é característico não apenas da filosofia humiana, mas da própria modernidade.

4 Poder-se-ia dizer, é verdade, que nosso filósofo afirma, no "Advertisement" que precede o Livro 3, que espera que essa parte de seu Tratado possa ser compreendido por "leitores comuns". Essa ideia parece ser reforçada no parágrafo inicial da Seção 1, que vem logo a seguir. Entretanto, o modo como Hume se expressa ao fim do livro, ao apresentar pela primeira vez a metáfora do pintor e do anatomista do modo como veremos a seguir, evidencia a ideia de que, no fim das contas, o fato de o autor ter esperanças de que o Livro 3 fosse compreensível para leitores "não-filósofos" não advém do fato de ele ter sido escrito para eles. "The anatomist ought never to emulate the painter; nor in his accurate dissections and protraitures of the smaller partes of the human body, pretend to give his figures any gracious and engaging attitude or expression. There is even something hideous, or at least minute in the views of things, which he presents; and 'tis necessary the objects shou'd be set more at a distance, and be more cover'd up from sight, to 
Os leitores familiarizados com a Seção 1 da primeira Investigação sabem que, futuramente, essa metáfora viria a ser associada a uma discussão sobre duas espécies de filosofia: a primeira, associada ao anatomista, seria consideravelmente abstrusa e consistiria em um trabalho minucioso de anatomia da natureza humana. A outra, pela qual, nesse texto, Hume parece nutrir uma estima que não era tão evidente no Tratado, é associada ao pintor e, mesmo sendo considerada como uma forma da ciência da natureza humana, tem por propósito representar a virtude da forma mais amigável para fazer com que os homens, influenciados principalmente em suas afecções, sejam incitados à prática de boas ações. Nesse ponto, parece-nos que a figura do pintor e a do anatomista são apresentadas, no que diz respeito às suas funções, de maneira semelhante àquela que pode ser observada no Tratado. Entretanto, a Seção 1 da Investigação sobre o Entendimento Humano apresenta inovações consideráveis. Isso fica particularmente evidente no parágrafo final desse texto, em que Hume considera que terá êxito se conseguir unir as duas espécies de filosofia sobre as quais acabara de discorrer. Essa tentativa de união é importante porque o homem, no contexto da primeira Investigação, é apresentado como um ser que é igualmente racional, social e ativo, de modo que a natureza recomenda para ele uma vida, por assim dizer, mista, que dê a devida atenção a essas diferentes características. Uma filosofia meramente abstrusa seria apenas causa de melancolia, tanto por conta das incertezas a que estaria submetida quanto por conta da recepção desfavorável que os trabalhos abstrusos tenderiam a receber ${ }^{6}$ (HUME 1999).

Não devemos pensar que Hume emprega, nesse momento, um artifício meramente retórico. A sua consciência de estar escrevendo para um público mais amplo que aquele restrito às universidades se evidencia, afinal, em outros momentos da primeira Investigação. Um deles, bastante explícito, está no final da Parte 1 da Seção 5, em que ele informa o leitor que, se ele não tiver gosto pelas ciências abstratas, poderá se abster da leitura da parte seguinte (HUME 1999, p. 124). Ora, esse tipo de advertência simplesmente não seria necessário se nosso filósofo não pretendesse realmente que o texto que vinha desenvolvendo até ali atingisse um tipo de leitor diferente

make them engaging to the eye and imagination. An anatomist, however, is admirably fitted to give advice to a painter; and "tis even impracticable to excel in the latter art, without the assistance of the former."

6 Parece que temos, aqui, em alguma medida, uma reafirmação de certos momentos melancólicos da Conclusão do Livro 1 do Tratado, mas não é só isso. Se no texto de juventude a filosofia, para que seja atividade prazerosa, deve ser praticada segundo o que nos dizem a natureza e nossas inclinações, o que Hume nos diz na Seção 1 da Investigação sobre o Entendimento Humano é que a filosofia deve se humanizar não apenas no que diz respeito a seu conteúdo ou a seus modos de investigação, mas também no que diz respeito à sua forma de exposição e ao público que deve buscar atingir. 
daquele que ele percebia como o "público alvo" do Tratado. É importante observarmos, ainda, que, inicialmente, a primeira Investigação recebeu o nome de Ensaios Filosóficos sobre o Entendimento Humano. Desse modo, se pensarmos que a forma ensaio é inegavelmente mais acessível que a forma tratado, e se atentarmos para o fato de a inspiração principal para o Hume ensaísta (ainda que esse não seja bem, ainda, o Hume da primeira Investigação) ser o Spectator, periódico de Addison e Steele que tinha entre seus propósitos declarados fazer com que a filosofia se tornasse acessível para o homem comum, torna-se bastante clara uma mudança importante no que diz respeito ao projeto filosófico de nosso autor: enquanto o Tratado mostrava o anatomista como aquele que deve auxiliar o pintor, mas não exercer a mesma atividade que ele, a primeira Investigação já se oferece, desde o início, como um livro que pretende, por meio da conciliação desses dois caracteres tão distintos, colaborar diretamente para a formação de um tipo de leitor que não é, necessariamente, o filósofo sisudo por quem se pretendia que o Tratado fosse lido ${ }^{7}$.

Devemos observar, a partir daí, que Hume, em seus textos posteriores ao Tratado, expandiu não apenas o público a que pretendia se dirigir, mas também os propósitos que pretendia que fossem atingidos por sua filosofia. Isso ficará bastante evidente se retomarmos, agora, as funções atribuídas à forma de ciência da natureza humana que está associada ao pintor: ela deve, como já vimos, representar a virtude de maneira amigável com o objetivo de incitar os homens a praticá-la. Desse modo, ao pretender conciliar esse primeiro caráter com o do anatomista, Hume pretende não apenas colaborar para o avanço das ciências. Ele pretende, também, que sua obra tenha algum tipo de influência sobre o homem comum. Quando se dedicar a textos morais, portanto, nosso autor não tratará apenas de descobrir os princípios pelos quais os homens estabelecem distinções morais, ou de estabelecer as normas de conduta mais apropriadas. Será preciso que os mesmos textos que explicam esse tipo de princípio tratem, também, de instilá-los em leitores que não poderão ser apenas aqueles a quem a filosofia oferecida no Tratado estava restrita.

7 Trata-se, portanto, de estabelecer uma filosofia que possa efetivamente interferir de algum modo na vida comum. Ainda que alguns autores, a exemplo de Donald Livingston (1998), tenham atentado para o fato de Hume pretender fazer uma "filosofia da vida comum", eles parecem se concentrar apenas no fato de que a filosofia é, no entender de nosso autor, algo que não deve se distanciar excessivamente da vida comum para que não chegue a conclusões absurdas. Falta-nos, ainda, um tratamento mais sistemático do modo como Hume concebe que a filosofia deve influenciar, de algum modo, a vida comum, colaborando para a formação do caráter daqueles que, apesar de imersos em uma vida mais ativa, devotam a ela alguma atenção. 
Alguns textos parecem indicar ainda um pouco mais que isso: na Seção 2 da Investigação sobre os Princípios da Moral, por exemplo, Hume parece pretender não apenas incitar a prática da benevolência, por um lado, e verificar, por outro, os motivos pelos quais ela vem a ser considerada uma virtude. De certa maneira, é como se a própria maneira escolhida pelo filósofo para explicar as razões pelas quais aprovamos ações ou caracteres benevolentes fosse, ao mesmo tempo, uma forma de incitação. Ora, ao fim da Parte 1 dessa seção, Hume nos informa que seu propósito, ali, não é recomendar a benevolência ou a generosidade, mas desenvolver um raciocínio especulativo pelo qual será possível chegar a conclusões acertadas sobre por que elas são consideradas virtudes. Segue-se, então, na Parte 2, uma série de exemplos práticos, extraídos da vida cotidiana, da história e de doutrinas de outros filósofos, que nosso autor elenca com o intuito de provar que a benevolência causa um sentimento de aprovação por conta de sua utilidade.

Evidentemente, seria temerário negar que, na Parte 2, Hume procede mais como filósofo especulativo do que como alguém que pretende recomendar a prática da virtude. Na Parte 1, o que vemos é um elogio da benevolência, que se segue a uma afirmação bastante enfática, no primeiro parágrafo, da aprovação que essa qualidade tende inexoravelmente a inspirar. Já a Parte 2 apresenta exemplos que são escolhidos cuidadosamente para levar à conclusão de que a utilidade é a causa pela qual aprovamos não apenas a benevolência, mas todas as chamadas virtudes sociais. Esse preceito, Hume faz questão de nos mostrar, permitiria até mesmo uma correção de nosso comportamento no que diz respeito à prática da benevolência e de outras virtudes ${ }^{8}$. Não está em questão, portanto, que nosso filósofo pretende chegar, como já havia anunciado, a conclusões especulativas bastante sólidas. Mais ainda, se era essa a finalidade declarada da Parte 2, não há por que defendermos que essa preocupação está ausente desse texto. Entretanto, é importante não perdermos de vista que um dos motivos pelos quais Hume pode se dedicar com tranquilidade à especulação é que, como ele mesmo nos informa de maneira suficientemente explícita,

“[...] não há qualidades mais merecedoras da boa-vontade e da aprovação gerais da humanidade que a benevolência e a humanidade, a amizade e a gratidão, a afecção

8 Isso fica particularmente evidente no parágrafo 18, em que o hábito de dar esmolas é condenado porque, apesar de parecer aliviar em grande medida o sofrimento dos indigentes, termina por incentivar a indolência e os excessos. Desse modo, por ser, na verdade, prejudicial às pessoas que deveria beneficiar, essa prática é apresentada por Hume como sendo mais uma fraqueza do que uma virtude. Ora se é verdade que tendemos naturalmente a aprovar aquilo que tende a promover o nosso bem ou o bem de outras pessoas, é verdade, também, que podemos nos enganar com relação a quais atos seriam os mais apropriados no que diz respeito a promover esse fim. 
natural e o espírito público, ou o que quer que proceda de uma simpatia terna com os outros, e uma preocupação generosa pela nossa espécie. Estas, onde quer que apareçam, parecem se transmitir por conta própria, de certa maneira, para cada observador, e invocar, por si próprias, os mesmos sentimentos afetuosos e favoráveis que exercem sobre todos ao redor. ${ }^{9}$ (HUME 1998, p. 79)

Parece, então, que o recurso frequente a exemplos por parte de Hume diz algo importante sobre os propósitos que ele passou a buscar atingir em seus textos morais. Ora, se a aparição de uma virtude social é, por si só, uma recomendação para a sua prática, na medida em que é capaz de exercer alguma influência sobre aqueles que a contemplam, parece justo pensar que um autor que desenvolve uma teoria sobre a virtude por meio da exposição frequente de situações em que ela ocorre espera, em alguma medida, que esse procedimento, ao fazer com que a virtude "apareça" para seus leitores, trate de influenciá-los de modo que se sintam dispostos a praticá-la. Nesse sentido, é possível dizer que o próprio modo de raciocinar escolhido por Hume tornouse, portanto, uma tentativa de conciliação das diferentes espécies de filosofia ${ }^{10}$.

Esse tipo de afirmação pode, é verdade, parecer um exagero. Entretanto, o desejo de atingir um público mais amplo e fazer da filosofia uma forma de entretenimento e de formação é explicitado por Hume em diversos outros textos. O mais conhecido deles é, provavelmente, o ensaio "Of Essay Writing”, no qual temos uma descrição bastante vívida das consequências nefastas da separação entre filosofia e vida comum. Nesse escrito, a filosofia de colégios e celas é apresentada como quimérica e ininteligível. O isolamento dos pensadores teria resultado na perda de uma facilidade de pensamento e de expressão que só poderia ser adquirida pela participação na vida social. A filosofia teria sido reduzida a ruínas e, se levarmos em conta que o mundo da conversação é grande fonte de experiência para o filósofo moral, não se poderia esperar que as coisas fossem muito diferentes (HUME 1985).

Antes de apresentar esse quadro desolador da filosofia que se isola da vida comum, porém, Hume trata de mostrar que esta última estaria condenada, por conta de tal separação, a sofrer consequências igualmente desoladoras, que podemos observar com facilidade na seguinte passagem:

9 "[...] no qualities are more entitled to the general good-will and approbation of mankind, than beneficence and humanity, friendship and gratitude, natural affection and public spirit, or whatever proceeds from a tender sympathy with others, and a generous concern for our kind and species. These, wherever they appear, seem to transfuse themselves, in a manner, into each beholder, and to call forth, in their own behalf, the same favourable and affectionate sentiments, which they exert on all around."

10 Estamos cientes, é claro, de que o uso de exemplos na segunda Investigação talvez tenha, também, o propósito de salientar o método experimental que Hume pretendeu utilizar. Ainda assim, parece claro que esse modo de proceder, além de ser consistente com a forma de coletar "experimentos" apresentada na Introdução do Tratado, cumpre, também, a função que defendemos aqui. 
Pois que possibilidade haverá de se encontrar tópicos de conversação adequados ao entretenimento de criaturas racionais sem que se recorra às vezes à história, à poesia, à política e aos princípios mais óbvios, ao menos, da filosofia? Deverá todo o nosso discurso ser uma série de fofas e observações fúteis? ${ }^{11}$ (HUME 1985, p. 534)

Em seguida, nosso filósofo trata de observar que, se assim for, o tempo que dedicarmos à vida social será não apenas a parte mais tediosa, mas também a mais inútil de nossas vidas.

Essa passagem torna bastante óbvia a percepção de que a filosofia não é capaz, por si só, seja de que variedade for, de transformar aqueles que se dedicam a ela em perfeitos cavalheiros, ou em pessoas que poderão ser consideradas companhias particularmente interessantes. Ela está inserida em algo como um quadro maior que inclui alguns outros tópicos. E ao dizer que não apenas a filosofia, mas também a história, a poesia e a política (talvez entre outras áreas) deverão contribuir para que o mundo da conversação seja agradável e proveitoso, Hume não está apenas elencando uma série de disciplinas que deverão, por assim dizer, ser estudadas pelas pessoas de boa companhia. Trata-se de construir uma base sólida a partir da qual será possível que os homens se tornem não apenas capazes de juízos mais sólidos, como, também, mais virtuosos e mais sociáveis. Entretanto, isso não seria possível por meio de estudos que privilegiassem argumentos excessivamente longos e, muitas vezes, distantes da experiência comum. Em um ensaio intitulado "Of the Study of History", por exemplo, Hume nos recomenda a história, entre outros motivos, porque os historiadores foram, praticamente sem exceção, "[...] os verdadeiros amigos da virtude, e sempre a representaram em suas cores apropriadas, ainda que possam ter errado em seus julgamentos de pessoas particulares ${ }^{12 "}$ (HUME 1985, p. 567). A referência, como nosso filósofo trata de evidenciar a seguir, é a Maquiavel, que teria mostrado grande amor pela virtude em sua História de Florença, mesmo tendo aconselhado todo tipo de vícios ao apresentar raciocínios de caráter mais geral em seu $O$ Príncipe.

É importante notarmos, ainda, que Hume afirma, algumas linhas acima, que a história tem sobre a prática do mundo a vantagem de fazer com que nos familiarizemos com os assuntos humanos sem diminuir os sentimentos mais delicados pela virtude. Esse aspecto, aliado às considerações sobre o amor dos historiadores pelas práticas que podemos ter como virtuosas, torna-se bastante

11 "For what Possibility is there of finding Topics of Conversation fit for the Entertainment of Rational Creatures, without having Recourse sometimes to History, Poetry, Politics, and the more obvious Principles, at least, of Philosophy? Must our whole Discourse be a continued Series of gossipping Stories and idle Remarks?"

12 "[...] the true friends of virtude, and have always represented it in its proper colours, however they may have erred in their judgments of particular persons." 
significativo porque permite que tracemos alguns comentários sobre o modo como Hume teria passado a acreditar, em textos posteriores ao Tratado da Natureza Humana, que a filosofia deve proceder. Ainda que não seja possível defender que textos como a Investigação sobre os Princípios da Moral realizam algo como uma história, certamente podem ser vistos como uma tentativa, por parte do autor, de evitar cadeias de raciocínio excessivamente longas e deslocadas da experiência que, além de serem bastante tediosas para o "novo público" que Hume pretendia atingir, certamente incorreriam em conclusões, para dizer o mínimo, indignas de confiança. Ora, um dos aspectos que nosso filósofo trata de reprovar nas morais do amor próprio é justamente o fato de que, independentemente do que as filosofias mais sofisticadas possam nos ensinar, as afecções sociais e benevolentes são prontamente atestadas pela experiência comum (HUME 1998, p. 165). Podemos concluir, então, que o autor de textos morais, se não desejar que seu fim seja o dos pensadores enclausurados que Hume nos apresenta em "Of Essay Writing", tem muito a aprender com o historiador. O recurso a exemplos, bem como uma forma de escrever que seja agradável, é essencial tanto para garantir que as conclusões alcançadas pelos filósofos não sejam meramente quimeras quanto para permitir que o homem comum se beneficie efetivamente delas ${ }^{13}$.

Podemos ver essas considerações como um complemento interessante para algumas outras, que Hume nos apresenta em um outro ensaio, intitulado "Of the Delicacy of Taste and Passion", cujo tema principal é bastante conhecido dos leitores da obra do filósofo escocês: nele, vemos as diferenças entre aquilo que será chamado a "delicadeza de paixão", uma tendência a se deixar afetar excessivamente por todos os acidentes da fortuna, e aquilo que

13 É verdade que Hume inicia "Of the Study of History" recomendando que as mulheres estudem história, e é verdade, também, que os motivos que motivam essa recomendação poderiam parecer, especialmente ao leitor contemporâneo, um tanto sexistas: segundo o nosso autor, esse seria um bom modo de as mulheres aprenderem que os homens têm defeitos e que não são governados apenas pelo amor, mas também por paixões como avareza, ambição e vaidade, entre muitas outras. Annette Baier (2010) considera que o modo ofensivo como Hume se refere às mulheres nesse ensaio teria sido o motivo pelo qual este teria sido suprimido nas edições dos Essays and Treatises on Several Subjects posteriores a 1760. Entretanto, a recomendação que nosso filósofo faz às mulheres, seja ela ofensiva ou não, em nada diminui as considerações posteriores sobre as vantagens do estudo da história, nem prejudica a sua inserção em um quadro no qual ela poderia contribuir com a formação do homem comum, e não apenas de mulheres que, diz Hume, teriam tido seu juízo prejudicado pela leitura de novelas. Além disso, parece-nos importante observar que a censura de Hume é não às mulheres, mas a certa maneira de conceber a formação do caráter delas. Se a história pode colaborar para que elas sejam mais sensatas, isso é possível justamente porque não está pressuposta qualquer disposição "natural”, por parte do belo sexo, a ver o mundo de maneira fútil e excessivamente romantizada. O que nosso filósofo pretende com as recomendações que faz às mulheres no início do texto é, então, mais a denúncia de um tipo de formação que seria pernicioso. Desse modo, somos obrigados a discordar de Baier quando ela afirma que o tratamento demeritório conferido às mulheres nesse ensaio teria sido o grande motivo para que Hume desistisse dele. 
Hume denomina a "delicadeza de gosto", que é a capacidade de discernir com grande precisão a beleza e a deformidade de qualquer tipo. A primeira delas, segundo o nosso filósofo, seria prejudicial. Ainda que aqueles que a possuem tenham prazeres mais intensos, são, também, extremamente mortificados por qualquer situação que não lhes agrade e, como sabemos, grandes prazeres são muito menos frequentes que grandes dores. Mesmo que não fosse assim, o caso é que não temos tanto controle quanto gostaríamos sobre as circunstâncias que nos atingem, o que por si só basta para tornar a delicadeza de paixão algo, por assim dizer, perigoso.

A delicadeza de gosto, por sua vez, é apresentada por Hume como bastante desejável. Ainda que seja verdade que o homem que tiver essa capacidade será afetado intensamente por todo tipo de deformidade, seja em uma obra literária ou no caráter de outrem, ela não é causa de grandes infelicidades porque, de maneira geral, podemos escolher os livros que lemos ou as companhias que cultivamos. Desse modo, ainda que as duas formas de delicadeza expandam em grande medida o campo de nossos prazeres e nossas dores, a delicadeza do gosto tenderá, no mais das vezes, a nos trazer felicidade. Mas a delicadeza do gosto não é importante apenas por fazer com que sejamos mais excitáveis por obras de arte de qualquer tipo: Hume chega a apresentá-la como uma espécie de remédio para as paixões mais violentas, as quais seriam consequências inescapáveis da delicadeza de paixão, e, após citar uma passagem de Ovídio segundo a qual o estudo das artes liberais humaniza o caráter, ele afirma que

[...] nada é tão benéfico à melhoria do temperamento quanto o estudo das belezas seja da poesia, da eloqüência, da música ou da pintura. Elas conferem uma certa elegância ao sentimento à qual o resto da humanidade é estranho. As emoções que elas excitam são suaves e ternas. Elas arrastam a mente para fora da pressa dos negócios e dos interesses, promovem a reflexão, dispõem à tranquilidade e produzem uma melancolia agradável que, de todas as disposições da mente, é a mais apropriada para o amor e a amizade. ${ }^{14}$ (HUME 1985, p. 7)

Como seria de se esperar, então, o cultivo do gosto está associado à busca de conhecimento das belezas a que ele se refere. Devemos nos lembrar, aqui, que a teoria moral humiana é apresentada de forma tal que a moralidade é, também ela, questão de gosto. Os sentimentos morais apropriados estariam

14 "[...] nothing is so improving to the temper as the study of the beauties, either of poetry, eloquence, music, or painting. They give a certain elegance of sentimento to which the rest of mankind are strangers. The emotions which they excite are soft and tender. They draw off the mind from the hurry of business and interest; cherish reflection; dispose to tranquillity; and produce na agreeable melancholy, hich, of all dispositions of the mind, is the best suited to love and friendship." 
condicionados à nossa capacidade de cultivar da maneira apropriada um gosto moral, que funcionaria de maneira análoga ao gosto aplicado às obras de arte. É interessante lembrarmos, também, das muitas vezes em que Hume fala em beleza da virtude e deformidade do vício. Isso está em consonância com a concepção de que a delicadeza do gosto seria, no fim das contas, algo que desenvolveria em nós os sentimentos mais apropriados não apenas no que diz respeito a julgar a beleza de uma pintura, um soneto ou uma sinfonia, mas também no que se refere às formas mais desejáveis de sociabilidade. Nesse quadro, é perfeitamente possível ver a filosofia, ao menos em parte, como algo que deve não apenas apresentar argumentos rigorosos, mas colaborar, também, para o cultivo do gosto.

Isso seria praticamente impossível para um filósofo escritor de tratados, e parece que Hume tinha plena consciência disso desde o começo. De qualquer modo, está suficientemente claro que as mudanças relativas à forma que percebemos nas obras de nosso filósofo não foram realizadas simplesmente para assegurar a fama literária, ainda que ela tenha sido, reconhecidamente, um dos grandes objetivos que ele buscou alcançar. Essas transformações revelam uma mudança naqueles que Hume considerava serem os próprios objetivos da filosofia. Ao escrever o Tratado da Natureza Humana, ele já considerava, como vemos na Conclusão do Livro 1, que a boa filosofia se faz com prazer, de acordo com nossas inclinações, mas seu grande interesse era estabelecer uma nova fundação para as ciências. Em textos posteriores, vemos com clareza que não bastava mais aproveitar os momentos em que a natureza nos inclina a filosofar para que nos dedicássemos alegremente a descobertas que pareciam não dizer respeito à ralé do lado de fora: tornou-se necessário para Hume que a filosofia fosse capaz de colaborar ativamente para tornar mais felizes e mais proveitosas as vidas daqueles que se dispusessem a dar a ela alguma atenção. Nosso filósofo poderia, é verdade, ter sido mais claro quanto aos modos pelos quais ela pode fazêlo. Como se sabe, Hume não nos legou considerações detalhadas acerca do que poderia ser um processo apropriado de formação, ou procedimentos específicos pelos quais a filosofia poderia colaborar com ele. Ainda assim, está claro que, a partir de certo momento, esse tipo de preocupação, ainda que não tenha sido necessariamente dominante em sua obra, incorporou-se definitivamente àquilo que ele acreditava que deveríamos esperar da atividade filosófica ${ }^{15}$.

15 Nesse sentido, não temos como concordar com Don Garrett (1997) quando ele afirma que a concepção que Hume tinha da filosofia permaneceu, de modo geral, constante ao longo de sua carreira. Seria possível, é claro, defender que nosso autor tinha desde o início uma preocupação em conciliar os aspectos especulativos e os mais, por assim dizer, práticos da filosofia, mas não teria sido capaz de fazê-lo quando escreveu o Tratado. Entretanto, essa não parece ser a posição de Garrett a respeito. 


\section{Referências bibliográficas}

BAIER, Annette. The Cautions Jealous Virtue: Hume on Justice. Cambridge; London: Harvard University Press, 2010.

GARRETT, Don. Cognition and Commitment in Hume's Philosophy. Oxford; New York: Oxford University Press, 1997.

HUME, David. An Enquiry concerning Human Understanding. Ed. Tom L. Beauchamp. Oxford; New York: Oxford University Press, 1999.

HUME, David. An Enquiry concerning the Principles of Morals. Ed. Tom L. Beauchamp. Oxford; New York: Oxford University Press, 1998.

HUME, David. Essays Moral, Political and Literary. Ed. Eugene F. Miller. Indianapolis: Liberty Fund, 1985.

HUME, David. The Letters of David Hume: Volume I - 1727 - 1765. Ed. J. Y. T. Greig. Oxford; New York: Oxford University Press, 2011.

HUME, David. A Treatise of Human Nature. Eds. David Fate Norton e Mary J. Norton. Oxford; New York: Oxford University Press, 2000.

LIVINGSTON, Donald. Philosophical Melancholy and Delirium: Hume's Pathology of Philosophy. Chicago: The University of Chicago Press, 1998.

POTKAY, Adam. The Passion for Happiness: Samuel Johnson and David Hume. Ithaca: Cornell University Press, 2000. 